
\title{
遗传资源获取与惠益分享相关国际制度新进展
}

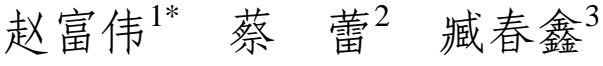 \\ 1 (环境保护部南京环境科学研究所, 南京 210042) \\ 2 (环境保护部自然生态保护司，北京 100035) \\ 3 (中国环境科学研究院, 北京 100012)
}

\begin{abstract}
摘要: 遗传资源获取与惠益分享相关国际制度涉及生物多样性保护、粮食安全、公共健康、知识产权以及国际贸 易等诸多领域。迄今, 《名古屋议定书》、《粮食和农业植物遗传资源国际条约》和《共享流感病毒以及获得疫 苗和其他利益的大流行性流感防范框架》是这一领域最富成效的国际制度范式，且相互具有可协调性。世界知识 产权组织在相关领域的谈判虽然已经形成了遗传资源、传统知识和民间文艺表达3份案文, 但各方在术语使用、保 护客体、保护范围等关键问题上分歧严重, 致使谈判举步维艰。世界贸易组织一直在讨论《与贸易有关知识产权 协定》和《生物多样性公约》的相互关系, 发展中国家呼吁多年的来源披露等相关要求遭到发达国家抵制。近年 来，虽然世界贸易组织争端解决机制支持了多起援引“环境保护例外”条款起诉的案例，但遗传资源提供国可以从 中汲取的可操作经验有限。世界知识产权组织和世界贸易组织等相关多边机制与《名古屋议定书》之间存在显见 的法理冲突, 制度上的变革与协调遥遥无期。相比之下, 区域贸易协定的双边模式更具现实操作空间, 可以纳入遗 传资源获取与惠益分享规则, 给予缔约方国内立法更大的灵活性和自由度，因而为协调这种冲突提供了一个新的 思路。但我们也应当注意到部分自由贸易协定的获取与惠益分享规则对 “私法合同模式” 的肯定，在一定程度上增 加了《名古屋议定书》实施效力的不确定性。
\end{abstract}

关键词：遗传资源；粮食安全；公共健康；知识产权；贸易

\section{Latest developments in international regimes relevant to access and ben- efit-sharing of genetic resources}

\author{
Fuwei Zhao ${ }^{1 *}$, Lei Cai ${ }^{2}$, Chunxin Zang ${ }^{3}$ \\ 1 Nanjing Institute of Environmental Sciences, Ministry of Environmental Protection, Nanjing 210042 \\ 2 Department of Nature and Ecology Conservation, Ministry of Environmental Protection, Beijing 100035 \\ 3 Chinese Academy of Environmental Sciences, Beijing 100012
}

\begin{abstract}
The international regimes regarding access and benefit-sharing of genetic resources (ABS) are closely related to multiple topics, including biodiversity, food security, public health, intellectual property, and international trade. Until now, the Convention on Biological Diversity (CBD), United Nations Food and Agriculture Organization (FAO), and World Health Organization (WHO) have developed some of the most effective model regimes separately in accordance with their respective mandates, namely, the Nagoya Protocol, the International Treaty on Plant Genetic Resources for Food and Agriculture (ITPGRFA) and the Pandemic Influenza Preparedness Framework for the Sharing of Influenza Viruses and Access to Vaccines and Other Benefits (PIPF). These multilateral conventions enable parties to fulfill their respective obligations in a coordinated manner. With respect to intellectual property rights (IPRs), the members of the World Intellectual Property Organization (WIPO) have managed to produce three drafts regarding aspects of IPRs including conserving genetic resources, traditional knowledge, and folklore. However, negotiation progress has been hindered due to substantial divergence among members over key issues, such as terms of use, subject matter, and scope of protection. With regard to international trade, discussions under the framework of World Trade
\end{abstract}

收稿日期: 2017-08-31; 接受日期: 2017-11-20

基金项目: 环境保护部“生物多样性保护”专项、环保部南京环科所中央级公益性科研院所基本科研业务专项(GYZX170105)

* 通讯作者 Author for correspondence. E-mail: zhaofuwei@outlook.com 
Organization (WTO) are still stuck on working out the complexities between CBD and the Agreement on Trade-related Aspects of Intellectual Property Rights (TRIPs), where developed members are steadfast in opposing developing countries' proposals on disclosure of the origin of genetic resources and associated traditional knowledge during the process of patent application. In recent years, although some appeals, which invoke exception clauses for environmental protection, have been sustained by WTO dispute settlement mechanisms, countries providing genetic resources still aren't yet able to draw readily practical references. There are obviously some legal conflicts among the Nagoya Protocol, WIPO, WTO, and other multilateral systems, and resolving such complexities poses difficulties. In contrast, the bilateral approach within the framework of the regional trade agreement (RTA) proves to be more practical and flexible in terms of integrating ABS rules, and providing parties with more domestic legislative freedom and flexibility, which therefore have ushered in a novel way of thinking for coordinating such dilemmas. Nevertheless, we need to be fully aware of the fact that the "private contract mode" favored by few RTAs would inevitably increase the uncertainties for effectively implementing the Nagoya Protocol to a certain extent.

Key words: genetic resources; food security; public health; intellectual property rights; trade

遗传资源是国家战略资源，是经济社会可持续 发展的基石, 也是国家生态安全和生态文明的重要 保障。根据1993年生效的《生物多样性公约》(CBD), “遗传资源”是指具有现实或者潜在价值的、来自动 植物和微生物或其他来源的任何含有遗传功能单 位的材料。CBD把“公平合理分享由利用遗传资源 而产生的惠益”作为三大目标之一，明确了获取和 利用遗传资源的三个基本原则，即国家主权原则、 事先知情同意原则和共同商定条件下公平分享惠 益原则。2010年, CBD缔约方大会第十次会议通过 了《获取遗传资源和公正公平分享其利用所产生惠 益的名古屋议定书》(以下简称《名古屋议定书》), 进 一步将国家主权、事先知情同意、共同商定条件下 公平分享惠益等三项原则制度化, 建立了遗传资源 及相关传统知识获取与惠益分享国际制度(薛达元, 2011)。

按照《名古屋议定书》相关规定, 获取遗传资 源时, 需要得到其原产国缔约方或者已经依据CBD 获取了资源的缔约方的事先知情同意, 而涉及土著 和地方社区的, 还应得到他们的事先知情同意或核 准和参与; 获取传统知识, 缔约方政府应采取立 法、行政或政策措施保障土著和地方社区的事先知 情同意或核准和参与权; 依照共同商定的条件, 公 平公正地分享惠益, 包括利用遗传资源和传统知识 所产生的惠益。各缔约方政府要酷情采取有效的立 法、行政或政策措施, 建立遗传资源获取与惠益分 享管理体制机制，加强国内获取与惠益分享立法和 执法, 保障遗传资源持有者和使用者的权益, 同时
还要为“非商业性研究”、“人类、动植物健康”、“粮 食安全”等特殊情形的获取和利用创造便利条件 (SCBD, 2012)。

实际上，遗传资源获取与惠益分享涉及的领域 极其广泛，诸如粮食和农业、知识产权、国际贸易、 公共健康等均与其密切相关(赵富伟和薛达元, 2008)。除CBD及其《名古屋议定书》外, 联合国多 个进程均涉及遗传资源获取与惠益分享。联合国粮 食和农业组织(FAO)和世界卫生组织(WHO)已经为 特定遗传资源建立了获取和惠益分享机制。世界知 识产权组织(WIPO)正在开展遗传资源、传统知识和 民间文艺表达的知识产权保护制度案文谈判。世界 贸易组织(WTO)持续开展了遗传资源相关知识产权 保护制度的讨论。联合国大会(General Assembly of the United Nations)正在就国家管辖范围外生物多样 性(biodiversity of areas beyond national jurisdiction, BBNJ, 含遗传资源获取与惠益分享)保护和利用制 度关键问题进行碰商。FAO和WHO相关制度的实施 必然对CBD及其《名古屋议定书》的执行产生影响, 如何协调不同国际法之间的关系成为缔约方面临 的现实问题。同时，尚在讨论或制定中的国际制度 也在密切关注《名古屋议定书》的实施进程, 而各 国构建新国际制度的过程势必推进对《名古屋议定 书》的法律解释，进而影响其实施效力。

\section{1 相关国际进程进展}

\section{1 《名古屋议定书》新进展}

自2014年生效以来, 全球已有 100 多个国家和 
地区批准或加入了《名古屋议定书》, 其决策机构 即缔约方大会业已召开两次会议。第一次会议基本 完成了初期建章立制工作, 为各缔约方切实履行 《名古屋议定书》奠定了坚实的制度基石(赵富伟等, 2015)。第二次会议于2016年12月召开, 审议通过了 遵约委员会议事规则, 完成了遵约委员会部分成员 的轮替, 审查了信息交换所、国际公认的遵约证书、 能力建设和发展战略框架等的执行情况。其中, 遗 传资源数字化序列信息(digital sequence information on genetic resources)的获取与惠益分享问题成为本 次会议上各方瞩目的焦点。各方围绕遗传资源数字 化序列信息是否应该适用《名古屋议定书》以及如 何获取与惠益分享展开了激烈讨论。发展中国家集 团认为遗传资源数字化序列信息是经过人为解译 的数字化产物, 本质上仍然是遗传资源, 应当适用 《名古屋议定书》确立的获取与惠益分享规则, 否 则将会削弱《名古屋议定书》的效力。发达国家集 团如日本、韩国、美国等对此极力反对，而欧盟、 澳大利亚、加拿大、新西兰等则以缺乏深入研究或 需在国内先行探讨为由, 极力拖延讨论进程。缔约 方大会考虑到此议题涉及大量技术问题, 决定先交 给技术专家组和科学、技术和工艺咨询附属机构讨 论, 再由大会下一次会议审议。

发展中国家的担忧主要缘于生物技术的快速 发展给《名古屋议定书》带来的挑战。诚然, 随着 生物信息学(Bioinformatics)、合成生物学(Synthetic Biology)、基因驱动技术(Gene Drives)的出现, 生物 产业对遗传资源的利用形式发生了巨大的变化, 使 用者不必取得遗传资源实物本身, 仅利用其数字化 序列信息就能够实现对遗传资源的研究、开发和商 业化利用(Dress et al, 2011; Jimenez-Sanchez \& Philp, 2016; Vasava, 2016)。遗传资源数字化序列信息的获 取、跨境转移和利用增加了提供国的遗传资源流失 风险, 威胁到作为提供国的发展中国家的利益, 使 得发展中国家苦心孤诣构建尚且不能尽如人意的 获取与惠益分享制度形同虚设, 给《名古屋议定书》 的实施带来了严峻挑战。因此, 巴西2015年将遗传 资源相关 “信息” 纳入 “遗传资源” 范畴, 适用国内遗 传资源获取与惠益分享立法 ${ }^{(}$。客观地说, 这不仅是 遗传资源数字化序列信息是否属于 “遗传资源”或

(1) 见巴西 2015 年第 13.123 号法律第 2 条。
“遗传资源利用”的科学或法律问题, 更多地是经济 和政治问题。发展中国家和发达国家将会在此问题 上形成持续的激烈交锋, 恐不亚于《名古屋议定书》 文本谈判。

\section{2 粮食和农业}

2001年11月3日, FAO第三十一届大会通过了 《粮食和农业植物遗传资源国际条约》(ITPGRFA)。 它是全球首个专门针对粮食和农业植物遗传资源 保护、可持续利用和利益分享的具有法律约束力的 国际多边协定。该条约的主要内容包括: 多边系统、 获取与惠益分享、农民权利以及可持续利用等 4 个 方面。

ITPGRFA承认各国对其粮食和农业植物遗传 资源(系指“对粮食和农业具有实际或潜在价值的任 何植物遗传材料”, 而 “遗传材料”指含有遗传功能单 位的有性和无性繁殖材料) 的主权, 同时为方便获 取这些资源以及公平分享相关利益, 建立粮食和农 业植物遗传资源获取与利益分享多边系统, 将64类 粮食和饲草(约占人类粮食种类的 $80 \%$ )农作物纳入 多边系统。多边系统内的遗传资源只能用于粮食和 农业相关研究、育种、培训和保存, 不包括化学、 药用或其他非食用(含饲用)工业用途, 禁止将其直 接申请专利、植物新品种等知识产权。ITPGRFA成 员须向所有缔约方开放利用其保存的这些作物资 源, 便利育种者、科学家和相关企业获取, 促进科 学研究、创新和信息交换。任何单位和个人利用通 过多边系统获取的遗传资源时, 都应通过信息交 流、技术获取和转让、能力建设商业利益共享等方 式分享相关利益。其中, 应将相关产品总销售额的 1.1\%返还到ITPGRFA的财务机制即信托基金。

截至2017年7月, ITPGRFA已经有144个缔约方, 中国尚未加入。自生效以来, ITPGRFA多边系统已 纳入了超过150万份植物遗传资源(BCMC, 2017)。 从数量来看, 缴存最多的是国际农业研究硅商小组 各国农业研究中心(国际农研中心)和欧盟, 每年通 过签署《标准材料转让协定》 (Standard Material Transfer Agreement, SMTA)交流的遗传资源超过10 万份(王述民和张宗文, 2011)。信托基金自2013年起 依据SMTA接收缴存资金。在不增加多边系统作物 种类的前提下, 至2030年, 每年缴存的资金有望达 到2,400万美元(Moeller \& Stannard, 2013)。然而, 由 于大量缔约方还没有将其拥有的粮食和农业植物 
遗传资源纳入多边系统, 以及掌握着主要基因库的 国家如中国、日本等没有加入ITPGRFA，信托基金 尚未形成稳定的资金流。

\section{3 知识产权}

\subsubsection{WIPO相关工作进展}

WIPO管理着多个涉及遗传资源和传统知识的 公约或条约, 如《专利合作条约》及其《实施细则》、 《世界版权公约》、《保护文学艺术作品伯尔尼公 约》等。早在 20 世纪 90 年代末, WIPO就成立了专门 的专家小组, 在 28 个国家开展传统知识持有人及其 知识产权需求现状的调查。2000年, WIPO成立了知 识产权与遗传资源、传统知识和民间文艺表达政府 间委员会(WIPO-IGC), 专门研究遗传资源获取与 惠益分享和传统知识保护等问题, 试图制定适用于 遗传资源、传统知识和民间文艺表达的知识产权保 护制度。到2017年6月底, WIPO-IGC已经召开了34 次会议, 形成了3份独立案文, 即遗传资源案文、传 统知识案文和民间文艺表达案文。但由于各方分歧 非常大, 在政策目标、术语使用、保护客体、受益 人、保护范围、权益管理、例外和限制等关键领域 难以达成一致, 进展十分缓慢。现有案文某种程度 上只是反映了各方的观点和立场。2017年10月初, WIPO-IGC把3份案文提交给WIPO成员国大会第五 十七届系列会议审议。这次会议授权WIPO-IGC在 2018年和 2019年继续召开6次会议, 同时设立 WIPO-IGC 2018-2019年会期特设专家组帮助制定 草案, 至2019年WIPO成员国大会评估相关进展后, 再决定是否召开外交会议, 抑或授权继续谈判 (WIPO, 2017)。

\subsubsection{WTO相关工作进展}

WTO框架下的 《与贸易有关的知识产权协定》 (TRIPs)生效于1995年1月1日, 是《关税和贸易总协 定》(GATT) 乌拉圭回合谈判的21个最后文件之一, 是当前世界范围内涉及面广、保护水平高、保护力 度大、执行力强的一个国际知识产权公约。该协定 第27条对 “可授予专利的客体”进行了规定：第 1 款 规定任何技术领域的发明只要满足所谓的新颖性、 创造性和实用性后均能够获得专利保护; 第2 款规 定了专利授权的公共秩序或道德例外; 第3 款许可 成员方排除部分标的的可专利性, 如动植物与生物 方法, 同时要求成员方采用专利或特殊制度(如植 物新品种保护制度)抑或两者结合来保护植物品种。
2001年, WTO通过了《多哈宣言》(Doha Ministerial Declaration), 要求TRIPs理事会审查TRIPs和CBD、 传统知识和民间文艺保护之间的关系。

一直以来, 关于 TRIPs和CBD的关系, WTO成 员之间主要有“无冲突”或“无实质冲突”和“固有冲 突”等观点(李明德, 2005; Laxman \& Ansari, 2013)。 总体上，发展中国家普遍坚持“无实质冲突”或“固 有冲突”观点, 持续地强烈要求修改TRIPs条款; 而 以美国、加拿大、日本为代表的发达国家集团坚持 “无冲突”观点, 反对修改TRIPs条款。发展中国家集 团分别于2006年、2008年、2011年向TRIPs理事会 提交了 3 份关于修改 TRIPs 的建议案文 (IP/C/W/ 474、TN/C/W/52、TN/C/W/59), 获得了超过100个 成员的支持。发展中国家主张: 第一, 在专利申请 环节，申请者应披露遗传资源及相关传统知识的来 源; 第二, 申请者应披露依据CBD及其《名古屋议 定书》相关规定所取得的获取与惠益分享合法证明, 即“国际公认的遵约证书”(internationally recognized certificate of compliance, IRCC); 第三, 各成员方应 采取立法或行政措施, 明确不披露来源或违法获取 的法律后果; 第四, 给予CBD秘书处TRIPs理事会 观察员身份, 向TRIPs理事会通报CBD及其《名古屋 议定书》相关信息。发达国家对这些主张要么坚决 反对, 要么避而不谈, 坚称WIPO-IGC正在开展遗 传资源及相关传统知识的知识产权保护制度谈判, WIPO才是解决这一问题的最有效场所。

2017年, TRIPs理事会分别于1月、3月和6月召 开了3次会议, 均涉及TRIPs第27条的审查、CBD与 TRIPs的关系、传统知识保护等 3 个议题。从最近一 次会议披露的情况来看, 发展中国家集团和发达国 家集团仍然各持己见, 根本分歧难以弥合, 甚至连 CBD秘书处观察员身份这一提案都没有得到美、 日、加等发达国家成员的正面回应。《多哈宣言》 通过已近20年, 但WTO-TRIPs框架下的遗传资源及 相关传统知识保护问题仍然裹足不前。

\section{4 国际贸易}

\subsubsection{WTO例外条款新发展}

环境保护(或生物多样性保护)一直被排斥于 WTO的多边贸易体制之外, 但随着各国对可持续 发展的重视, 贸易与环境的天平出现了向环境保护 倾斜的趋势。《1994年关税与贸易总协定》 (GATT1994) 和《服务贸易总协定》(GATS) 是WTO 
成员为促进商品和服务贸易自由化而缔结的多边 国际规则, 旨在削减关税和其他贸易壁垒, 消除国 际贸易中的差别待遇。

GATT1994和GATS 是WTO法律框架的重要组 成部分, 其确立的“自由”(降低关税)、“非歧视”(国 民待遇和最惠国待遇)、“例外与免责”(一般例外和 安全例外)等多项主要原则, 共同构成了WTO一揽 子协定的基本原则与基础。其中, “例外与免责” 主要 是指GATT1994和GATS中的“一般例外”条款和“安 全例外”条款。而“一般例外”条款涉及环境保护、人 类健康、生物资源保护等内容，称为“环境保护例 外”。具体而言, 货物领域的环境保护例外条款主要 是GATT1994第20条(b)和(g)项, 而服务贸易领域的 则主要是GATS第14条“一般例外”(b)项。这些条款 允许WTO成员在为“保护人类、动物或植物的生命 或健康”、“有效保护可能耗竭的天然资源”等特定情 形出现时, 暂时停止执行WTO协定所赋予的国际 法义务, 可以采取“必须的”、“不得构成武断的或不 合理的差别待遇, 或构成对国际贸易的变相限制” 的措施。

近年来, 在 WTO争端解决机制审理的诸多案 例中, 专家组报告和上诉机构报告均支持了数起援 用GATT1994第20条相关规定起诉的案例(陈卫东, 2002)。这些案例一方面为WTO成员援引“环境保护 例外”条款保护生物多样性积累了成功经验; 另一 方面也促进了WTO一揽子协定中例外条款制度的 发展。

\subsection{2 区域贸易协定中的遗传资源获取与惠益分 享规则}

另一个值得注意的趋势是, 区域贸易协定 (Regional Trade Agreement, RTA)正在成为WTO成 员处理遗传资源获取与惠益分享问题的新的国际 进程。自1995年至2016年底, WTO已登记643项区域 贸易协定, 其中431项已经生效(WTO, 2017)。每个 WTO成员都签订有区域贸易协定, 多的近30项。区 域贸易协定已经成为后WTO时代各国促进区域贸 易、实现区域贸易自由化的重要手段, 特别是自由 贸易协定(Free Trade Agreement, FTA)。

自由贸易协定的内涵十分广泛, 既有货物和服 务贸易、投资准入、知识产权等WTO传统项目, 也 有环境、劳工、电子商务等非WTO传统项目。自由 贸易协定的相关规则往往高于GATT1994、GATS等
WTO一揽子协定的既定规则, 例如: 知识产权相关 章节出现了要求更高、标准更严的TRIPs+条款, 如 实验数据保护; 新增的环境相关内容则注重与CBD 的密切联系, 突出生物多样性保护相关规则; 引入 来源披露促进传统知识保护等方面。

以2013年签订的《中国-瑞士自由贸易协定》 为例, 第11章“知识产权保护”专门规定了 “遗传资 源和传统知识”, 强调双方促进TRIPs和CBD相互支 持, 采取措施保护生物多样性和公平分享相关惠益, 引入遗传资源和传统知识的来源披露制度及其法 律后果。比较耐人寻味的是, 美国尽管不是 $\mathrm{CBD}$ 非 缔约方, 但其向来抵制 $\mathrm{CBD}$ 和《名古屋议定书》框 架下的遗传资源获取与惠益分享安排, 主张由使用 者和提供者直接签订私法合同来共享惠益(薛达元 和蔡蕾, 2007)。但在美国与秘鲁、哥伦比亚签订的 自由贸易协定中, 其态度有所缓和, 策略有所不同, 如赞同事先知情同意原则、公平分享相关惠益、提 高专利实质性审查条件等 ${ }^{1}$ 。

\section{5 公共健康}

2008年，世界卫生大会提出制定一份涵盖大流 行性流感病毒(influenza virus with human pandemic potential)、共享信息(包括基因序列数据)以及疫苗 和医疗产品等利益分配的大流行性流感防范框架, 协调和规范各国政府间对特殊病原体的协同防控 和资源共享。2011年, 第六十四届世界卫生大会通 过了《共享流感病毒以及获得疫苗和其他利益的大 流行性流感防范框架》( 以下简称PIP防范框架), 建 立了PIP生物材料 ${ }^{2}$ (pandemic influenza preparedness biological materials)的获取与惠益分享机制。值得注 意的是, PIP防范框架界定的“PIP生物材料”并不包 含“基因序列数据”。

PIP防范框架坚持病毒共享和利益共享对等的 原则，承认“国家对其生物资源拥有主权权利”，同 时也认为各国应该“采取集体行动”降低公共卫生风 险，支持通过WHO全球流感监测和应对系统的152

１）见《美国-秘鲁自由贸易协定》《《美国-哥伦比亚自由贸易协定》中“生 物多样性”相关章节与“关于生物多样性和传统知识的谅解”。

(2) 据《共享流感病毒以及获得疫苗和其他利益的大流行性流感防范框 架》第 4.1 条, “PIP 生物材料”包括“人类临床标本; 野生型的人类 H5N1 病毒及其他可能引起人类大流行的流感病毒的病毒分离物; WHO 全球 流感监测和应对系统实验室从 H5N1 或其他可能引起人类大流行的流感 病毒中开发的经改造的病毒……还包括从野生型 H5N1病毒及其他可能 引起人类大流行的人类流感病毒中提取的核糖核酸和包含一个或多个 病毒基因的整个编码区的互补脱氧核糖核酸”。 
个实验室共享病毒, 分别制定了针对系统内、外接 受方的具有一定适用期限的“标准材料转让协议”。 对系统内的接受者而言, 需要按照WHO的规定和 相关科学准则使用PIP生物材料, 不谋求标的材料 的任何知识产权; 而系统外的接受者则还应向 WHO捐赠或以WHO支付得起的价格出售疫苗、抗 病毒药物或诊断包, 抑或免费或以优惠条件授权发 展中国家制药商实施其知识产权, 同时支持发展中 国家特定流感实验室的能力建设。截至2016年, PIP 生物材料惠益分享机制已经收到各类捐赠资金超 过2,800万美元, 大流行性流感病毒疫苗3.5亿剂, 极大地促进了对大流行性流感的防范和应对工作。

2016年, WHO专家组审查认为, PIP防范框架正 在得到充分实施, 其作为全球公共卫生的一种基础 性互惠模式, 可以应用于其他病原体, 但目前的范 围应当继续侧重于大流行性流感(WHO, 2017a)。专 家组审查报告同时认为基因序列数据对流感研究 愈发变得重要, 建议会员国在不能迅速交换PIP生 物材料但有基因序列数据时, 应当立刻共享基因序 列数据, 并促进其在可持续数据库中公开获取。 2017年, 第七十届世界卫生大会决议要求WHO秘 书处研究将季节性流感病毒等其他病原体纳入 PIP 防范框架的影响, 以及将基因序列数据纳入PIP防 范框架惠益分享机制的影响(WHO, 2017b)。

\section{2 《名古屋议定书》与相关领域的协调与冲突}

\section{1 《名古屋议定书》与粮食安全和公共健康的协调}

《名古屋议定书》第4条“与国际协定和文书的 关系” 规定了处理与其他相关国际法关系的若干项 原则, 即: 在“支持并且不违背CBD和议定书的目 标” 前提下, (1) 《名古屋议定书》不妨碍现有任何国 际协定赋予缔约方的权利和义务; (2)不妨碍缔约方 今后制定和执行其他相关国际协定; (3)缔约方应以 相互支持的方式执行 《名古屋议定书》和其他国际 协定; (4)《名古屋议定书》不适用于“获取与惠益分 享专门性国际文书”(Specialized International Access and Benefit-sharing Instrument)的缔约方。因此, 我 们并不能依据 “后法优于先法” 原则 (万鄂湘等, 1998), 理想地认为各缔约方应当优先履行 《名古屋 议定书》的权利和义务。

在粮食安全领域, 《粮食和农业植物遗传资源 国际条约》缔约方担心 《名古屋议定书》确立的双
边获取与惠益分享模式会对粮食和农业植物遗传 资源获取与惠益分享多边机制形成挑战, 影响作物 育种和科学研究。在公共健康领域, WHO成员也担 心 《名古屋议定书》的实施可能会在流感病毒的共 享方面产生不确定因素, 特别是双边谈判可能会延 误病毒获取, 增加全球卫生安全风险。目前, 欧盟 等缔约方主张PIP防范框架属于“获取与惠益分享专 门性国际文书”。第七十届世界卫生大会相关决议 认为PIP防范框架就是PIP生物材料获取与惠益分享 的“专门性国际文书”, 希望这一法律地位得到《名古 屋议定书》缔约方大会的认可。

显然, 《名古屋议定书》和ITPGRFA、PIP防范 框架存在交叉的可能, 而解决这一问题的关键在于 划清各自的界限, 需要《名古屋议定书》进一步明 确“获取与惠益分享专门性国际文书”的甄别程序和 标准。而《名古屋议定书》缔约方大会第二次会议 已经决议开展相关研究, 制定获取与惠益分享专门 性国际文书的标准和确认程序, 预计将在2018年达 成共识。此外, 《名古屋议定书》第8(b)条和第8(c) 条实际上也为“粮食安全”和 “公共健康”规定了 “特 殊考虑”, 缔约方应为这些情形下的获取与惠益分 享提供便利。因此, 在涉及64类粮食和农业植物遗 传资源或特定病原体的获取与惠益分享时, 有望厘 清《名古屋议定书》和ITPGRFA或PIP防范框架的 适用边界, 促进相关国际法之间的协调和相互支持。

\section{2 《名古屋议定书》与知识产权制度的冲突}

就知识产权领域而言，尽管《名古屋议定书》 与知识产权相关国际制度在目标等方面存在差异, 但从善意履行国际法的视角来看, 《名古屋议定书》 缔约方有义务将违反获取与惠益分享法律的行为 定性为违法行为, 而违法行为得利则不应受缔约方 国内法律保护; 另一方面, 《名古屋议定书》第15 条和第16条要求缔约方“采取适当、有效和适度的 立法、行政或政策措施” 处理违法获取行为, 这与现 行专利规则保护发明的义务存在某种程度的抵触, 特别是违反获取与惠益分享法律的知识产权法律 后果等问题(谢新明, 2011)。《名古屋议定书》与 WIPO和WTO-TRIPs构建的知识产权制度之间的法 理冲突是显而易见的, 不能简单地适用《维也纳条 约法公约》 (Vienna Convention on the Law of Treaties) 第30条“关于同一事项先后所订条约之适用” 和习惯 法一般原则解决。 
关于来源披露相关要求, 发展中国家在WIPO 和WTO-TRIPs山重水复疑无路之时, 却在区域贸易 协定和国内立法中柳暗花明又一村。除中国外, 欧 盟在自由贸易协定中持开放态度，与哥伦比亚、秘 鲁的自由贸易协定都采取了具体的立法措施, 协调 知识产权和生物多样性保护的关系, 包括在来源披 露及其法律后果方面给予国内立法更大自由度。自 由贸易协定对来源披露相关要求的包容, 在推动遗 传资源和传统知识保护上具有相当的合理性和优 势(陈默, 2014)。因此, 越来越多的国家采用区域贸 易协定+国内立法的方式, 协调获取与惠益分享和 知识产权制度的关系。这些立法实践势必形成对 WIPO和WTO-TRIPs的制度突破, 推动相关国际法 发展与变革。

\section{3 《名古屋议定书》与国际贸易制度的冲突}

就贸易领域而言, 《名古屋议定书》与WTO“非 歧视原则”的冲突也是显而易见的。《名古屋议定 书》的立法意图具有天然的“御外” 性质, 即防止非 本国实体不当获取和利用本国遗传资源。这与WTO 确立的“国民待遇”等原则冲突，而“环境保护例外” 条款并非化解冲突的良药。倘若贸易与环境的天平 过度倾斜, 例外条款必然被滥用, 有违WTO的目 标。专家组和上诉机构为避免这种滥用对贸易自由 化和经济可持续发展造成负面影响, 必然倾向于宽 泛解释贸易规则而狭义解释“环境保护例外”, 进而 形成贸易利益高于环境利益的判例法, 不利于遗传 资源提供国(王辉, 2010)。另外, “环境保护例外”条 款本质上也并不支持对国内和国外实体采用不同

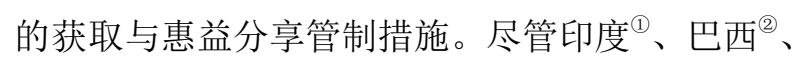
菲律宾 ${ }^{3}$ 等生物多样性大国普遍在国内获取与惠益 分享立法中采取 “内外有别”的管制措施, 但仍然需 要解决与WTO“非歧视原则”的协调问题。

区域贸易协定中的遗传资源获取与惠益分享 规则增加了《名古屋议定书》执行效力的不确定性。 一方面, 部分区域贸易协定强化了对《名古屋议定 书》的支持, 如《中国-瑞士自由贸易协定》，而另 一方面, 部分区域贸易协定却在削弱《名古屋议定 书》的效力, 如《美国-秘鲁自由贸易协定》和《美

(1) 见印度 2002 年《生物多样性法》第 3、4 条。

(2) 见巴西 2015 年第 13.123 号法律第 11 条

(3) 见菲律宾政府 1995 年第 247 号行政令第 3 条, 环境与自然资源部 1996 年第 $96-20$ 号部门行政令第 6、8 条。
国-哥伦比亚自由贸易协定》。美国虽然在协定中支 持“事先知情同意”和“公平分享惠益”原则，但这两 个区域贸易协定至少对《名古屋议定书》的执行和 后续谈判带来3个方面的冲击。第一, 从体例上来看, 获取与惠益分享规则均被写入 “关于生物多样性和 传统知识的谅解”, 而非协定正文的 “生物多样性” 章节, 弱化了获取与惠益分享规则的法律效力。第 二，美秘、美哥协定都强调了私法合同可以“充分 地”解决获取与惠益分享问题, 饱受发展中国家诟 病的“私法合同模式”在区域贸易协定中正当化。第 三，秘鲁和哥伦比亚在协定中放弃了发展中国家一 贯坚持的来源披露相关主张, 转而迎合美国要求的 公开知识产权信息和提升专利审查质量, 增加了自 身国内执法义务。尽管区域贸易协定对实现发展中 国家的来源披露相关要求具有积极作用, 但其对 “私法合同模式”的鼓励却对 《名古屋议定书》的实 施产生了负面效应, 也将毫无疑问地影响到WIPO 和WTO有关遗传资源的讨论。

\section{3 对策建议}

我国是《生物多样性公约》及其《名古屋议定 书》的缔约方, 是FAO、WIPO、WTO、WHO等多 个国际组织的成员, 在参与相关国际规则的制定与 实施过程中, 均不同程度地涉及到遗传资源获取与 惠益分享。另外, 我国近年加快了诸双边自由贸易 协定的谈判和缔结, 也在知识产权、环境或生物多 样性等章节涉及到遗传资源的保护和持续利用。遗 传资源保护与持续利用国家对策的多公约(或国际 组织)之间的协调成为亟待解决的现实问题。

\section{1 深化履约支撑技术研究工作}

国际法是不断变化和发展的, 然而, 在处理遗 传资源获取与惠益分享相关国际法的相互关系时, 不能简单地适用 “后法优于先法” 原则。各国在履行 相关国际法权利和义务时, 《名古屋议定书》并不 必然优先于ITPGRFA、WIPO诸公约或WTO一揽子 协定。多公约履约协调问题是同为多个公约缔约方 的各国政府面临的共同问题。国内应持续加强履约 支撑技术研究工作, 为协调履约奠定坚实的科技基 础。具体应深化以下 4 个方面的研究工作: 第一, 抓 紧开展相关国际法协同履约研究。在深入研究我国 乃至其他国家协同履约实践的基础上，提出遗传资 源相关国际制度协同推进的创新方案, 推动相关国 
际法发展，协调遗传资源保护和利用的制度冲突。 第二, 持续、定期开展全国范围的遗传资源本底调 查。遗传资源不同于物种资源, 其兼具有形性和无 形性等特征, 变异大、更新快, 应当持续、定期地 开展全国范围的资源普查工作。目前, 农业、林业 等部门已开展了部分专类如作物地方品种的本底 调查, 环境保护部组织实施的“生物多样性保护重 大工程”(Major Projects on Biodiversity Conservation) 涉及遗传资源本底调查, 相关遗传资源调查特别是 全国范围的普查工作应该持续和定期进行。第三, 定期开展遗传资源产业化调查, 重点查明我国遗传 资源相关产业发展现状、技术优势、知识产权保护 与实施、遗传资源进出口贸易等方面的情况, 明确 遗传资源保护需求和生物产业发展需求。第四, 研 究制定全国遗传资源保护和利用战略、规划或计划, 统筹协调遗传资源的国内保护和国际履约工作。

\section{2 加强《名古屋议定书》焦点议题的国内研究}

我国是生物多样性大国, 遗传资源十分丰富, 长期以来一直是遗传资源提供国; 同时, 随着国内 生物产业快速发展, 近年也加大了对国外遗传资源 的利用, 具备成为使用国的潜力。这一现实国情决 定了国家遗传资源保护和持续利用政策，也决定了 政府在国际谈判中所采取的立场和策略。当前, 有 关部门应尽快开展遗传资源数字化序列信息、知识 产权制度和遗传资源获取与惠益分享制度衔接机 制、《名古屋议定书》与WTO一揽子协定相互关系 等国际法研究, 形成符合国情的遗传资源保护与持 续利用国家立场, 积极参与相关国际法的制定和 后续谈判。同时, 还应加强对自由贸易协定的研究 和评估, 重视其对遗传资源保护与可持续利用的积 极作用。

\section{3 进一步健全国家遗传资源管理工作协调机制}

按照我国现行法律法规, 遗传资源保护、知识 产权、国际贸易、粮食与农业、公共卫生等分别由 不同的主管部门进行管理, 形成了多部门分工负责 的管理制度和体制。当前, 国务院设立了中国生物 多样性保护国家委员会, 承担生物多样性保护重大 战略的制定和实施，协调环保、农业、知识产权、 林业、中医药等25个相关主管部门的生物多样性保 护和管理工作。此外, 经国务院批准, 环境保护部 牵头建立由 17 个部委参加的生物物种资源保护部 际联席会议制度，统一组织、协调国家生物物种资
源(含遗传资源)保护和管理工作。现有协调机制尚 有进一步强化职能的空间, 需要加强对遗传资源相 关国际法谈判和国内相关制度建设的工作协调，特 别是要加强我国在遗传资源相关国际法框架下的 国家立场协调。

\section{参考文献}

Biodiversity Clearing-House Mechanism of China (BCMC) (2017) Accession of the United States of America to the International Treaty on Plant Genetic Resources for Food and Agriculture. http://www.biodiv.gov.cn/lygz/lydt/201708/ t20170811_419595.html. (accessed on 2017-8-20)

Chen M (2014) Negotiations of gene resources and traditional knowledge protection under the framework of Free Trade Agreement and our coping strategies. Journal of Henan University (Social Science), 54(5), 53-61. (in Chinese with English abstract) [陈默 (2014) FTA框架下遗传资源及传 统知识保护谈判与我国的应对策略. 河南大学学报 (社会 科学版), 54(5), 53-61.]

Chen WD (2002) Explanations on WTO’s Exception Clauses. University of International Business and Economics Press, Beijing. (in Chinese) [陈卫东 (2002) WTO例外条款解读. 对外经济贸易大学出版社, 北京.]

Dress L, Hessel A, Cai Y, Meyers JV, Moreira A (2011) Synthetic biology: an overview. In: Comprehensive Biotechnology (ed. Murray MY), pp. 629-640. Academic Press, Burlington.

Jimenez-Sanchez G, Philp J (2016) Genomics and the bioeconomy: opportunities to meet global challenges. In: Genomics and Society (eds Kumar D, Chadwick R), pp. 207-238. Elsevier, Califorlia.

Laxman L, Ansari AH (2013) The interface between TRIPs and CBD: efforts towards harmonisation. Journal of International Trade Law and Policy, 11, 108-132.

Li MD (2005) Relationship between TRIPs agreement and CBD, traditional knowledge and folklore. Journal of Guizhou Normal University (Social Science), (1), 20-23. (in Chinese with English abstract) [李明德 (2005) TRIPs协议 与《生物多样性公约》、传统知识和民间文学的关系. 贵 州师范大学学报(社会科学版), (1), 20-23.]

Moeller NI, Stannard C (2013) Identifying Benefit Flows: Study on the Potential Monetary and Nonmonetary Benefits Arising from the ITPGRFA. United Nations Food and Agriculture Organization, Rome.

Secretariat of the Convention on Biological Diversity (SCBD) (2012) Nagoya Protocol on access to genetic resources and the fair and equitable sharing of benefits arising from their utilization to the Convention on Biological Diversity. SCBD, Montreal.

Vasava DS (2016) Application of biotechnological techniques for medicinal plant research. Forest Research, 5, 191-194. 
Wan EX, Shi L, Yang CM, Deng HW (1998) International Treaty Law. Wuhan University Press, Wuhan. (in Chinese) [万鄂湘, 石磊, 杨成铭, 邓洪武 (1998) 国际条约法. 武 汉大学出版社, 武汉.]

Wang H (2010) Harmony between negotiation and conflicts of treaties: case study in the context of trade-environmental discuss. Yangtze Tribune, (4), 54-58. (in Chinese) [王辉 (2010) 谈判协商与条约冲突之协调——“贸易一环境” 论 争语境下相关成案的启示. 长江论坛, (4), 54-58.]

Wang SM, Zhang ZW (2011) The implementation progress on the International Treaty on Plant Genetic Resources for Food and Agriculture. Journal of Plant Genetic Resources, 12, 493-496. (in Chinese with English abstract) [王述民, 张宗文 (2011) 《粮食和农业植物遗传资源国际条约》实 施进展. 植物遗传资源学报, 12, 493-496.]

World Health Organization (WHO) (2017a) Review of the Pandemic Influenza Preparedness Framework. http://apps.who.int /gb/e/e_wha70.html. (accessed on 2017-11-2)

World Health Organization (WHO) (2017b) Seventieth World Health Assembly Update, 25 May. http://www.who.int/me diacentre/news/releases/2017/health-assembly-polio/en/. (accessed on 2017-11-2)

World Intellectual Property Organization (WIPO) (2017) IGC: What Is Happening Now. http://www.wipo.int/tk/en/igc/sna pshot.html. (accessed on 2017-11-3)

World Trade Organization (WTO) (2017) Annual Report 2017, pp. 88-91.

Xie XM (2011) On the conflicts between Nagoya Protocol and TRIPs, and its reconciliation: focus on the relationship between proper access to genetic resources norms and patent norms. Journal of Lanzhou Commercial College, 27, 122-126. (in Chinese with English abstract) [谢新明 (2011) 论《名古屋议定书》与TRIPs之冲突关系及其协调一一以 遗传资源的适当获取规则与专利规则之关系为切入点. 兰州商学院学报, 27, 122-126.]

Xue DY (2011) Analysis for the main elements and potential impacts of Nagoya Protocol. Biodiversity Science, 19, 113-119. (in Chinese with English abstract) [薛达元 (2011) 《名古屋议定书》的主要内容及其潜在影响. 生物多样 性, 19, 113-119.]

Xue DY, Cai Lei (2007) Progress on negotiation of international regime on access to and benefit-sharing of genetic resources under the Convention on Biological Diversity. Environmental Protection, 35(11B), 72-74. (in Chinese) [薛达 元, 蔡蕾 (2007) 《生物多样性公约》遗传资源获取和惠 益分享国际制度谈判进展. 环境保护, 35(11B), 72-74.]

Zhao FW, Xue DY (2008) International trends of and state legislation on access and benefit sharing of genetic resources. Journal of Ecology and Rural Environment, 24, 92-96. (in Chinese with English abstract) [赵富伟, 薛达元 (2008) 遗传资源获取与惠益分享制度的国际趋势及国家 立法问题探讨. 生态与农村环境学报, 24, 92-96.]

Zhao FW, Xue DY, Wu JY (2015) Hot spots and proposed actions of negotiations of the Nagoya Protocol after it functions. Biodiversity Science, 23, 536-542. (in Chinese with English abstract) [赵富伟, 薛达元, 武建勇 (2015) 《名古 屋议定书》生效后的谈判焦点与对策. 生物多样性, 23, 536-542.]

(责任编委: 杨庆文 责任编辑: 时意专) 